\title{
PESOS, RENDIMENTOS E PERDAS DA CARCAÇA DE CORDEIROS CORRIEDALE E MESTIÇOS ILE DE FRANCE x CORRIEDALE, TERMINADOS EM CONFINAMENTO ${ }^{1}$
}

\author{
WEIGHTS, YIELDS AND LOSSES OF CORRIEDALE AND ILE DE FRANCE $x$ \\ CORRIEDALE LAMBS, REARED UNDER FEEDLOT CONDITIONS
}

\author{
Edson Ramos de Siqueira ${ }^{2}$ Simone Fernandes ${ }^{3}$
}

RESUMO

$O$ experimento teve por objetivo comparar os cordeiros da raça Corriedale com mestiços (F1) Ile de France $x$ Corriedale, quanto às variáveis: peso da carcaça, porcentagem de quebra ao resfriamento e rendimentos de carcaça. Trabalhouse com 18 cordeiros de cada genótipo, desmamados aos 60 dias de idade, com 10 a $12 \mathrm{~kg}$ de peso vivo e terminados em regime de confinamento total, onde dispunham à vontade de uma ração com $15 \%$ PB e $70 \%$ NDT. Foram abatidos com peso vivo entre 30 e $32 \mathrm{~kg}$. Não houve diferenças entre os grupos genéticos para as variáveis estudadas, embora estas estejam dentro das requisições do mercado regional atual. Observou-se valor médio de $4 \%$ de perda no peso de sacrifício, em relação ao peso de origem. $O$ peso elevado de alguns componentes não constituintes da carcaça (cabeça, pele, sangue e fígado) representou $20,9 \%$ do peso vivo médio ao sacrifício e afetou negativamente o rendimento da carcaça. Os resultados obtidos não invalidam por si só, a utilizacão deste cruzamento em circunstâncias semelhantes, tendo em vista que outras variáveis envolvidas com a eficiência global do sistema de produção não foram estudadas e mostram que, a pesos vivos semelhantes, não existe diferença de genótipo sobre as perdas por transporte e resfriamento, e sobre rendimento de carcaça.

Palavras-chave: carcaça, carne de cordeiro, produção de carne, ovino.

\section{SUMMARY}

This study was carried out in order to evaluate the live weight at slaughter, carcass weights, cooling weight losses and carcass yield, for 18 Corriedale and 18 Ile de France $x$ Cor riedale lambs. They were weaned at 60 days of age, with 10 to $12 \mathrm{~kg}$ of live weight, and were reared in feedlot system. Both groups were fed with a $15 \% \mathrm{CP}$ and $70 \%$ TND diet, until to reach $30-32 \mathrm{~kg}$ of live weight when they were slaughtered. The results showed similarity between genotypes, although all carcasses presented the standard wished by the regional market. It was observed a $4 \%$ weight loss from the farm to the slaughterhouse. The head, pelt, blood and liver, represented $20.9 \%$ of the mean live weight at slaughter and affected the carcass yield. The similarity between groups does not become invalid the utization of crossbred lambs in the same conditions, because the global efficiency of the production system was not evalueted.

Key words: carcass, meat production, lamb meat, sheep.

\section{INTRODUÇÃO}

O cruzamento industrial, com a utilização de raças especializadas na produção de lã ou de dupla aptidão, na linha materna, e raças especializadas para produção de carne na linha paterna, é uma opção para os sistemas de produção de carne ovina no Brasil. O estudo destes sistemas, nas mais diversas regiões criatórias, deverá levar em consideração variáveis quantitativas, que caracterizem adequadamente as carcaças produzidas. Assim, a partir do peso vivo, pode se estimar o peso da carcaça e de seus principais cortes (GUERREIRO et al., 1986; GAILI, 1992), e dessa maneira, utilizá-lo para realizar a seleção de animais para sacrifício (LIMA et al., 1990). Por outro lado, o peso vivo tomado na origem, pode sofrer perdas até o sacrifício, devido ao

${ }^{1}$ Projeto financiado pela FAPESP (92/ 4903-7).

${ }^{2}$ Engenheiro Agrônomo, Professor Adjunto, Departamento Produção e Exploração Animal, UNESP/Botucatu, 18618 000, Botucatu, SP.

E-mail: fmvz unesp@laser.com.br. Autor para correspondência.

${ }^{3}$ Zootecnista, DPEA - UNESP/Botucatu. 
tempo e às condições do jejum, como também duração, época e condições do transporte (BRASAL \& BOCCARD, 1977)

As peculiaridades produtivas de cada país, determinam o tipo de produto que se oferece ao mercado, que tem sido modelado de acordo com as tradições culinárias e a preferência dos consumidores; e, dessa maneira, encontram-se grandes variações no peso das carcaças, em nível mundial e nacional (SAÑUDO et $\boldsymbol{a l} .$, 1992). Desse modo, o peso médio mundial da carcaça está ao redor de $15 \mathrm{~kg}$, que coincide com os dos maiores produtores (antiga URSS e Nova Zelândia), estando os menores pesos nas regiões leiteiras dos países Mediterrâneos (7kg), enquanto que as carcaças mais pesadas (14-22kg) são produzidas pela Grã-Bretanha, Irlanda e países Centro Europeus (SAÑUDO et al.1992). KLEEMANN et al. (1990) compararam cordeiros Merino com mestiços Polled Dorset X Merino, sacrificados aos 150 dias de idade, tendo constatado maior peso de carcaça nos mestiços $(18,07 \mathrm{~kg})$ do que nos puros $(16,80 \mathrm{~kg})$.

O rendimento de carcaça é muito variável no ovino (45 a $60 \%$ ), em função de um conjunto de fatores como: base genética, sexo, idade, peso vivo, peso ao nascer (SAÑUDO \& SIERRA, 1986), número de horas em jejum, dieta imposta aos animais e condição corporal (GALVÃO et $\boldsymbol{a l}$., 1991). Para CAÑEQUE et $\boldsymbol{a l}$. (1989), o rendimento verdadeiro ou biológico da carcaça é o mais preciso sob o ponto de vista experimental, já que, para calculá-lo, elimina-se o conteúdo digestivo, que é parte importante do ruminante vivo. ZUIBAROV et al. (1991) observaram que animais mestiços apresentaram efeito da heterose sobre o rendimento da carcaça, contrariando os resultados de SAÑUDO et al. (1981), em cujo trabalho, animais puros da raça Rasa Aragonesa tiveram um maior $(\mathrm{P}<0,01)$ rendimento de carcaça $(48,89 \%)$ que os mestiços Romanov x Rasa Aragonesa $(46,63 \%)$.

Este estudo teve por objetivo comparar cordeiros da raça Corriedale com mestiços Ile de France $\mathrm{x}$ Corriedale, recriados e terminados em confinamento, sacrificados a pesos similares, quanto às variáveis peso vivo ao abate, peso da carcaça, porcentagem de quebra ao resfriamento e rendimento da carcaça.

\section{MATERIAL E MÉTODOS}

O experimento foi conduzido na Faculdade de Medicina Veterinária e Zootecnia da UNESP, Campus de Botucatu. Trabalhou-se com 36 cordeiros inteiros, sendo 18 da raça Corriedale e 18 mestiços (F1) Ile de France X Corriedale. Todos os ani- mais eram da mesma origem e permaneceram com as mães, exclusivamente em pasto, até a desmama. Esta foi efetuada aos 60 dias de idade média, com peso vivo de 10 a $12 \mathrm{~kg}$. A terminação dos cordeiros foi realizada em regime de confinamento total, onde dispunham, à vontade, de uma ração com $15 \%$ de proteína bruta e $70 \%$ de Nutrientes Digestíveis Totais, com a seguinte composição: $35 \%$ de feno de Cynodon dactylon, cv. "coast cross"; 22,55\% de milho moído; $21,35 \%$ de farelo de algodão; $20 \%$ de esterco de galinha; $0,60 \%$ de calcário; $0,20 \%$ de premix vitamínico-mineral e $0,20 \%$ de sal iodado.

A pesagem dos animais era realizada semanalmente, até que atingissem o peso vivo na origem, localizado na faixa de 30 a $32 \mathrm{~kg}$. Observaramse as seguintes variáveis: peso vivo na origem, tomado no local de criação antes dos cordeiros iniciarem o jejum e serem transportados ao local de sacrifício (localizado a $45 \mathrm{~km}$ do confinamento, onde permaneciam aproximadamente 18 horas exclusivamente com dieta hídrica); peso vivo ao sacrifício, obtido anteriormente à degola; peso vivo vazio, que é o peso vivo ao sacrifício menos o conteúdo do aparelho gastrintestinal; peso da carcaça quente, obtido logo após o término da evisceração da carcaça; peso da carcaça fria, registrado após resfriamento da carcaça por 24 horas, a $4^{\circ} \mathrm{C}$.

Calculou-se: o rendimento de carcaça na origem (relação entre o peso da carcaça fria e o peso vivo na origem); o rendimento verdadeiro (relação entre o peso da carcaça quente e o peso vivo vazio); o rendimento comercial (relação entre o peso da carcaça fria e o peso vivo ao sacrifício). A comparação entre os dois genótipos foi efetuada, segundo método estatístico de ZAR (1984), utilizando-se para as variáveis quantitativas o Teste t para duas amostras independentes, com a determinação da média para indicação da tendência central.

\section{RESULTADOS E DISCUSSÃO}

Observa-se através dos resultados apresentados na Tabela 1, para as variáveis do peso vivo, que não houve diferenças significativas entre cordeiros da raça Corriedale e mestiços Ile de France $x$ Corriedale. Para o peso vivo na origem, isto é natural, uma vez que o mesmo foi pré-estabelecido, como referência para o sacrifício. O período de jejum e as condições de transporte até o abatedouro, promovem perdas, conforme constatações de SAÑUDO \& SIERRA (1986). Entretanto, neste experimento, o peso médio ao sacrifício foi $1,3 \mathrm{~kg}$ menor que o peso obtido na origem 18 horas antes, em ambos os grupos, redundando numa perda de $4 \%$ em relação ao peso na origem. Este valor se 
Tabela 1. Médias e desvios-padrões para as variáveis do peso vivo $(\mathrm{kg})$, nos dois grupos genéticos.

\begin{tabular}{lcc}
\hline VARIÁVEIS & PUROS & MESTIÇOS \\
\hline PESO VIVO NA ORIGEM & $32,15^{\mathrm{a}} \pm 0,95(3,0)^{1}$ & $32,13^{\mathrm{a}} \pm 0,52(1,6)$ \\
PESO VIVO AO SACRIFÍCIO & & \\
PERDAS NO & $30,85^{\mathrm{a} \pm 0,77(2,5)}$ & $30,80^{\mathrm{a}} \pm 0,55(1,8)$ \\
TRANSPORTE(kg) & $1,15^{\mathrm{a}} \pm 0,42(36,5)$ & $1,25^{\mathrm{a}} \pm 0,43(34,4)$ \\
& & \\
\hline
\end{tabular}

${ }^{1}$ Os valores entre parênteses referem-se aos coeficientes de variação.

ça, além do produto ser encontrado esporadicamente. Não se tem idéia, desta forma, qual a real preferência do mercado consumidor brasileiro, fato que de um lado é positivo, pois permite que se determine pesos ótimos econômicos de sacrifício, possibilitando atingir elevada eficiência de produção. Assim, ao observar os pesos médios das carcaças, deste experimento (Tabela 2), entende-se que são compatíveis com as requisições do atual mercado informal regional, além de tratar-se de valores que, a princípio, enquadram-

enquadra na faixa citada por OSÓRIO (1992), o qual, para um jejum de 17 a 18 horas, com água, admite-se perdas de até 5,5-6,0\% do peso vivo.

Visto que essas perdas ocorrem e são variáveis, comprova-se que a comercialização baseada no peso vivo pode implicar em erros e prejuízos econômicos ao produtor ou ao comprador, sendo mais preciso, estabelecer como referência, o peso da carcaça, como ocorre nos mercados desenvolvidos. Aliado a isso, é importante lembrar que, para não haver um aumento dessas perdas, os abatedouros devem estar próximos às zonas de acabamento, evitando-se o transporte de animais vivos a lugares muito distantes, e melhorando-se ao máximo as condições do mesmo.

Também quanto à variável peso vivo ao sacrifício, os grupos experimentais foram similares, resultado que se opõe aos de FIGUEIRÓ (1970); OSIKOWSKI \& BORYS (1976); LIRETTE $\boldsymbol{e t}$ al. (1984); RODRIGUES et al. (1984); PELLE et al. (1987) e FERNANDES et al. (1988), que ressaltaram o efeito benéfico promovido pelo cruzamento, sobre essa variável. No entanto, os referidos autores estipularam uma idade, e não um peso de sacrifício, o que permitiu que se evidenciassem diferenças entre cordeiros puros e mestiços, tendo sido esses últimos, sempre superiores. Poder-seia esperar diferentes pesos de sacrifício entre os grupos genéticos, já que, conforme discutido anteriormente, as perdas sofridas, durante o jejum e o transporte, efletem-se no peso. Como essas perdas não diferiram, obtiveram-se pesos de sacrifício semelhantes entre os tratamentos.

Ainda hoje, em nível de Brasil, os ovinos são sacrificados sem levar em conta critérios de qualidade, inexistindo uniformidade em relação à idade dos animais e pesos de carca-
Tabela 2 - Médias e desvios-padrões para as variáveis do peso da carcaça $(\mathrm{kg})$ e porcentagem de quebra ao resfriamento (\%), nos dois grupos genéticos.

\begin{tabular}{lcc}
\hline VARIÁVEIS & PUROS & MESTIÇOS \\
\hline PESO CARCAÇA QUENTE & $12,05^{\mathrm{a}} \pm 0,49(4,0)^{1}$ & $12,12^{\mathrm{a}} \pm 0,65(5,4)$ \\
PESO CARCAÇA FRIA & $11,62^{\mathrm{a}} \pm 0,52(4,5)$ & $11,78^{\mathrm{a}} \pm 0,62(5,3)$ \\
QUEBRA RESFRIAMENTO & $3,54^{\mathrm{a}} \pm 2,02(57,0)$ & $2,83^{\mathrm{a}} \pm 1,36(48,0)$ \\
& &
\end{tabular}

${ }^{1}$ Os valores entre parênteses referem-se aos coeficientes de variação. 
Tabela 3. Médias e desvios-padrões para as variáveis do rendimento da carcaça(\%), nos dois grupos genéticos.

\begin{tabular}{lrl}
\hline VARIÁVEIS & PUROS & MESTIÇOS \\
\hline REND. ORIGEM & $36,17^{\mathrm{a}^{*} \pm 1,92(5,3)^{1}}$ & $36,63^{\mathrm{a}} \pm 1,93(5,3)$ \\
REND. VERDADEIRO & $47,09^{\mathrm{a}} \pm 2,81(6,0)$ & $47,53^{\mathrm{a}} \pm 3,52(7,4)$ \\
REND. COMERCIAL & $37,71^{\mathrm{a}} \pm 1,89(5,0)$ & $38,21^{\mathrm{a}} \pm 2,07(5,4)$ \\
\hline
\end{tabular}

Os valores entre parênteses referem-se aos coeficientes de variação.

quando comparados com os puros, conforme constatou OSÓRIO (1992), tendo salientado que animais especializados para a produção de carne, possuem rendimentos superiores. Entretanto, isso não ocorreu com os cordeiros do presente experimento, tendo os puros, oriundos de raça de dupla aptidão (lã e carne), proporcionado o mesmo rendimento de carcaça, que os mestiços resultantes do acasalamento da raça mista com a raça paterna, especializada para a produção de carne. Provavelmente, poder-se-ia obter maiores valores de rendimento para as carcaças experimentais, se uma dieta de melhor

origem, não houve diferença significativa entre os cordeiros puros e mestiços, discordando de alguns trabalhos da literatura, como o de LOPEZ DE TORRE et al. (1984). Isso era esperado, já que os pesos na origem e da carcaça fria, conforme já discutido anteriormente, não diferiram entre os grupos. Neste experimento, o peso médio geral do conteúdo gastrintestinal foi de $5,27 \pm 0,88 \mathrm{~kg}$, e o peso vivo vazio médio, de $25,63 \pm 1,31 \mathrm{~kg}$. Desse modo, os valores de rendimento verdadeiro foram similares, discordando de SIERRA (1970), que confirmou interesse do cruzamento industrial na elevação do rendimento da carcaça ovina, tendo o mesmo, no entanto, trabalhado com maior peso de carcaça $(15 \mathrm{~kg})$.

As carcaças dos cordeiros puros e mestiços também foram similares quanto ao rendimento comercial, contrariando a superioridade dos mestiços, obtida nos experimentos de PELLE et al. (1987); HUIDOBRO \& JURADO (1989); ZUIBAROV (1991); FREDERIKSEN (1991), e dos puros (SAÑUDO et al., 1981), cujos rendimentos superiores foram atribuídos ao maior grau de gordura, quando comparados com os mestiços.

O peso elevado de determinados componentes, não constituintes da carcaça, podem afetar negativamente seu rendimento, principalmente a cabeça, a pele, o sangue e o fígado (LOPEZ et al., 1992). Os resultados obtidos para esses componentes, neste experimento, confirmam essa premissa. Em termos de média geral, constataram-se valores de $1,82 \pm 0,31 \mathrm{~kg}$ para a cabeça, $2,83 \pm 0,42 \mathrm{~kg}$ para a pele, $1,33 \pm 0,18 \mathrm{~kg}$ para o sangue e $0,46 \pm 0,05 \mathrm{~kg}$ para o fígado, correspondendo ao somatório de $6,44 \mathrm{~kg}$, que representou $20,9 \%$ do peso vivo médio ao abate. Há que se considerar ainda que a pele pode apresentar grande variabilidade quanto ao seu peso, em função da quantidade de lã que contenha.

Esperar-se-ia que os cordeiros mestiços apresentassem maiores rendimentos de carcaça, valor nutritivo tivesse sido empregada, já que a alimentação pode afetar significativamente o rendimento e a qualidade da carcaça, independentemente do grau de sangue, conforme demonstrou SIQUEIRA (1983). Entretanto, buscou-se utilizar uma dieta compatível com o nível genético dos animais, os quais eram provenientes de rebanho em processo inicial de melhoramento. A prova disto, foi o ganho de peso médio diário de $150 \mathrm{~g}$, observado ao longo do período experimental; considerado aquém das expectativas.

A inexistência de diferenças entre os genótipos não invalidam, por si só, a utilização deste cruzamento, em circunstâncias semelhantes, tendo em vista que outras variáveis envolvidas com a eficiência global do sistema de produção não foram estudadas.

\section{CONCLUSÕES}

Cordeiros Corriedale e Ile de France $\mathrm{x}$ Corriedale, sacrificados a pesos semelhantes não diferem quanto aos caracteres quantitativos da carcaça, os quais, no entanto, apresentam-se compatíveis com as requisições do atual mercado regional. A perda de peso entre a origem e o momento do sacrifício, associada às peculiares variações do rendimento, enaltecem a subjetividade da comercialização baseada no peso vivo, ressaltando a necessidade de se estabelecer como referência, o peso da carcaça. A estratificação dos componentes não constituintes da carcaça permitem verificar que alguns deles, sobretudo cabeça, pele, sangue e fígado, além do conteúdo gastrintestinal, podem promover, com as variações de seus pesos, importantes oscilações no rendimento da carcaça.

\section{REFERÊNCIAS BIBLIOGRÁFICAS}

BONIFACINO, L., KREMER, R., ORLANDO, D. et al. Estudio comparativo de corderos Corriedale y Corriedale por Texel. 2 Pesos al nascer, ganancias diarias y caracteristicas de la carcasa. Revista Veterinária, v. 70, p. 63-71, 1979. 
BRASAL, T.L., BOCCARD, R. Efectos de los tratamientos ante mortem sobre la calidad de la canal y la carne de cordero. INIA, Série Prodcción Animal, n. 8, p. 97- 125, 1977.

CAÑEQUE, V., HUILDOBRO, F.R., DOLZ, J.F., et al. Producción de carne de cordero Madrid: Ministério de Agricultura Pesca y Alimentación, 1989, 520 p.

CARVALHO, J.B.P., PEDROSO, J.R., FIGUEIRÓ, P.R.P Alguns fatores que afetam o rendimento de carne ovina. Rev Centro de Ciências Rurais, v. 10, n. 2, p. 95-104, 1980.

ESPEJO, M., MORA, M., GARCIA,L. Crecimiento y calidad carnicera de los productos obtenidos por cruzamiento entre moruecos de razas prolíficas y ovejas de razas locales españolas. In: INIA, Série Producción Animal, v. 8, p. 55-67, 1977.

FERNANDES, A.P., THORAT, B.P., DESHMUKH, A. P. Effect of crossbreeding on growth performance, carcass traits and meat characteristics in Deccani (native) sheep. In: WORLD CONGRESS ON SHEEP AND BEEF CATTLE BREEDING, 3, 1988. Proceedings... p. 483-486.

FIGUEIRÓ, P.R.P. Produção de cordeiros para abate. Revista Veterinária, v. 5, p. 260-6, 1970.

FIGUEIRÓ, P.R.P. Efeito do cruzamento da raça Hampshire Down e Romney Marsh na produção de cordeiros para abate. Rev Centro de Ciências Rurais, v. 9, p. 421-428, 1979.

FREDERIKSEN, J.H. Design of crossbreeding trial. Tidsskrift for Dansk-Faeavl, v. 56, n. 8, p. 4-6, 1991. In: Animal Breeding Abstract, v. 59, p. 999, 1991. (Abstract...).

GAILI, E.S.E. Breed and sex differences in body composition of sheep in relation to maturity and growth rate. Journal Agricultural Science, v. 118, p. 121-6, 1992.

GALVÃO, J.G., FONTES, C.A.A., PIRES, C.C. et al Caracterização e composição física da carcaça de bovinos não castrados, abatidos em três estágios de maturidade de três grupos racias. Revista Sociedade Brasileira Zootecnia, v. 20, p. $502-12,1991$.

GUERREIRO, J.L.V., OSÓRIO, J.C.S., FARIAS, J.V.C. et al. Avaliação da produção de carne em novilhos Hereford. In: REUNIÃO ANUAL DA SOCIEDADE BRASILEIRA DE ZOOTECNIA, 23, 1986, Campo Grande. Anais... Campo Grande: Sociedade Brasileira de Zootecnia, 1986, p. 317

GÜNEY, O., BICER,O. The fattening performance and carcass characterístics of Awassi X Awassi, Ile de France X Awassi(F1) and Chios $X$ Awassi first backcross (B1) ram lambs. World Review Animal Production, v. 22, p. 63-7, 1986.

HUIDOBRO, F., JURADO, J.J. Meat production of crossbred Manchega sheep. Invest Agrar Prod Sanid Anim, v. 4, n. 1 p. $35-44,1989$.

KLEEMANN, D.D., SMITH, D.H, GRIMSOM, R.J et al. Carcass and non-carcass characteristics of Suffolk-sired lambs from South Australian Merino, Poll Dorset x Merino and Border Leicester x Merino ewes. Small Ruminant Res, v. 3, p. 283 90, 1990

LIMA, N.M., GUERREIRO, J.L.V., OSÓRIO, J.C.S. et al. Predição da quantidade de carne do quarto e da paleta em carcaças de borregos Ideal e cruzas Ideal X Texel. In: REUNIÃO ANUAL DA SOCIEDADE BRASILEIRA DE ZOOTECNIA, 27, 1990, Campinas. Anais... Piracicaba: Sociedade Brasileira de Zootecnia, 1990, p. 813.

LIRETTE, A., SEOANE, J.R., MINVIELLE, F. et al. Effects of breed and castration on conformation, classification, tissue distribution, composition and quality of lamb carcasses. Journal Animal Science, v. 58, n. 6, p. 1343-1357, 1984.

LLOYD, W.R., SLYTER, A.L., COSTELLO, W.J. Effect of breed, sex, and final weight on feedlot performance, carcass characteristics and meat palatability of lambs. Journal Animal Science, v. 51, p. 316-320, 1983.

LOPEZ DE TORRE, G; MORENO, J.M.; GARCIA, E.A. Comparación del crecimiento y caracteristicas de las canales de corderos hijos de padre Merino y Madre F1 (Romanov x Merino).19. Revista Instituto Nacional Investigacion Agrária (INRA), v. 19, p. 141-150, 1984.

LOPEZ, M., COLOMER-ROCHER, F., RODRIGUEZ, M.C., et al. Producción de carne en la raza Lacha. 1. Rendimento de la canal y componentes del quinto cuarto de lechales, ternascos y corderos. In: ACTAS DE LAS JORNADAS CIENTIFICAS, Pamplona, 1991, SOCIEDAD ESPAÑOLA DE OVINOTECNIA E CAPRINOTECNIA: Depart. de Agric., Ganaderia y montes del Gobierno de Navarra, Pamplona, 1992. Anales...

OSIKOWSKI, M., BORYS, B. Effect on production and carcass quality characteristics of wether lambs of crossing Blackheaded Mutton, Ile de France and Texel rams with Polish Merino ewes. Livestock Production Science., v. 3, p. 343-9, 1976

OSÓRIO,J.C.S. Estudio de la calidad de canales comercializadas en el tipo ternasco segun la procedencia: bases para la mejora de dicha calidad en Brasil. Zaragoza, 1992, 335 p. Tese (Doutorado em Veterinaria) - Facultad de Veterinaria, Universidad de Zaragoza, 1992.

PELLE, E., PACSONYI, V., LAJOS, S. Results of crossing Ile de France with Merino sheep. Allattenyesztes-es-Takarmanyosas, v. 36, p. 331-7, 1987. In: Animal Breeding Abstract, v. 55, p. 866,1987 . (Abstract...).

RODRIGUES, C.O.; SELAIVE, A.; COSTANZI, A.R. Avaliação de cordeiros Ideal e cruzas com Ile de France, Texel, Hampshires Down, e Suffolk. Boletim Informação Instituto Pesquisa Zootecnia Francisco Osório, n. 11, p. 31-32, 1984.

SAÑUDO, C., PIEDRAFITA, J., SIERRA, I. Estudio de la calidad de la canal y de la carne en animales cruzados Romanov por Rasa Aragonesa. 2. Comparación en el tipo comercial ternasco con Rasa Aragonesa en pureza. In: JORNADAS CIENTÍFICAS DE LA SOCIEDAD ESPAÑOLA DE OVINOTECNIA, 7, 1981, Talavera de la Reina. Anales... Zaragoza: 1981, p. 483-489

SAÑUDO, C., SIERRA, I. Calidad de la canal en la especie ovina. Ovino, n. 1, p. 127-153, 1986

SAÑUDO, C., GONCALEZ, C., DELFA, R. El peso de la canal. Revista Ovis, v. 19, p. 9-19, 1992

SIERRA, I.A. La conformación en el ganado ovino: su influencia en el rendimiento canal y en el despiece. Intituto 
de Economia y Producciones Ganaderas del Ebro. C.S.I.C Univers. de Zaragoza, v. 5, p. 1-4, 1970.

SILVEIRA, P.M., OSÓRIO, J.C.S., JARDIM, P.O.C., et al. Efeito da raça sobre o peso vivo e características da carcaça em ovinos. In: REUNIÃO ANUAL DA SOCIEDADE BRASILEIRA DE ZOOTECNIA, 17, 1980, Fortaleza. Anais... Fortaleza: Sociedade Brasileira de Zootecnia, 1980. p. 112.

SIQUEIRA, E.R. Desempenho e características de carcacas de cordeiros machos e fêmeas da raça Ideal e cruzas Texel $x$
Ideal, criados em pastagem nativa. Pelotas, 1983, 130 p. (Mestrado em Produção Animal) - Faculdade de Agronomia, Universidade Federal de Pelotas 1983.

ZUIBAROV, M.M., GADZHIEV, G.M.R., GASANOV, Y.S. Ovtsevodstvo, v. 4, p. 31, 1990. In: Animal Breeding Abstract, v. 59, p. 336, 1991. (Abstract...).

ZAR, J.H. Biostatistical analysis 2.ed. Englewood Cliffs: Prentice Hall, 1984, 718 p

Ciência Rural, v. 29, n. 1, 1999. 